\title{
Design and implementation of ZigBee wireless bus monitoring system
}

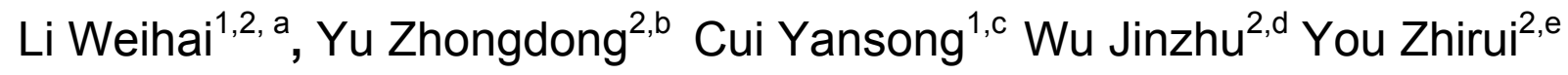 \\ ${ }^{1}$ Beijing University of Posts and Telecommunications, Beijing, P.R.China \\ ${ }^{2}$ Beijing Aerospace Zhitong Traffic Technology Co., Ltd. \\ aliweihai@bupt.edu.cn, b yuzhd@96900.com.cn, cuiys@bupt.edu.cn, dijinzhu.wu@urban-its.cn, \\ ezhirui.you@urban-its.cn
}

Keywords: ZigBee. Internet of Vehicles.

\begin{abstract}
With the advantages of low cost and low power consumption, Zigbee is widely used in internet of vehicles. In a big city has a large number of bus and other passenger transport vehicle, there is a strong demand for unified bus operation scheduling and monitoring system. This paper described the design and implementation of a vehicle network system based on ZigBee wireless network. This system can help the management of entry and parking in passenger station through the ZigBee network. After the actual deployment and testing, the project achieve the expected goal..
\end{abstract}

\section{Introduction}

Internet of things is a multi-functional wireless network including data collection, transmission and processing. Compared with traditional wired networks, it is more convenient to build a network, suffered less impact from the environmental, need lower power consumption and lower cost[1]. ZigBee is one of the typical short-range wireless communication technologies, which has been widely used in a certain application areas including the family network, control network, mobile phones and other mobile terminals [2].

As an important part of the Internet of things, in recent years the development of Internet of Vehicles is fast[3]. Internet of Vehicles usually based on WiFi, $3 \mathrm{~g} / 4 \mathrm{G}$ mobile network. Due to the low power consumption, less communication cost, and other advantages, ZigBee become an important technology used in vehicle network [4] [5] [6]. In the process of development that using the Zigbee technology in wireless sensor network, as the transmission power of all on-chip wireless communication system is very low, coupled with the receiver sensitivity is also fixed at a certain level, communication range of wireless sensor networks is limited, commonly a hundred meters or so[7] [8].

In this paper, the a city bus monitoring and management system based on ZigBee network is proposed. The ZigBee terminals are equipped in the vehicles and bus station. The network is formed among the ZigBee terminals. It realizes the small terminal with low power consumption and low cost. The ZigBee can connect more than 5000 devices in the network simultaneously. Moreover, the ad-hoc function and multi-hop function are equipped.

\section{Overall design}

As shown in Fig.1 and Fig.2, the bus monitoring system consists of two parts. The server part is used for storing and processing data. The other part is communication layer. Communication layer includes gateway (sink node), bus station terminal (RSU Road Site Unit) and vehicle terminal (OBU Onboard Unit).

Design of OBU.OBU mainly consists of five modules: ZigBee wireless communication module, RS232 bus communication module, CAN bus communication module, 485 module, and battery power management module.

ZigBee wireless communication module is mainly used to upload the OBU information, the driver license and RSSI summary information; RS232 bus communication module is mainly use to read the 
driver information from the ZTM216 module(Storage of bus driver information); CAN bus module is mainly used to read information of vehicles, such as speed, amount of oil; 485 bus module is used to read the peripheral information; battery power management module the vehicle is in a rest, vehicles entering the battery mode to power management role. The design of the terminal hardware schematic diagram is shown in Fig.3.

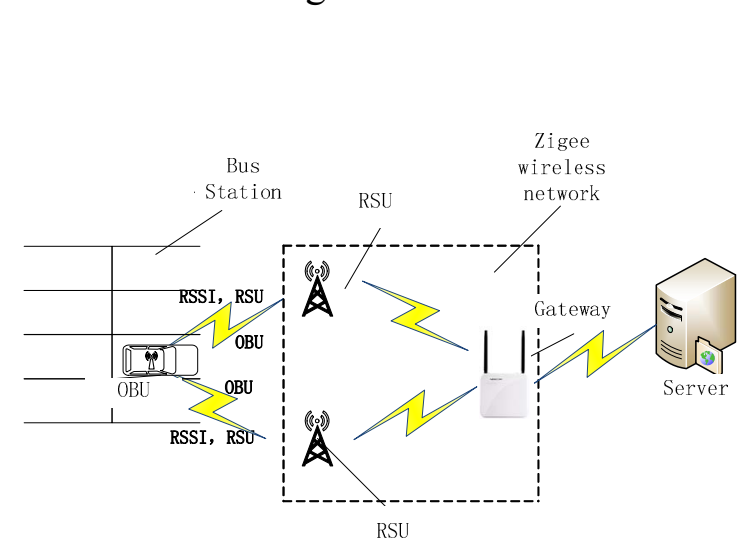

Fig1 System deploy

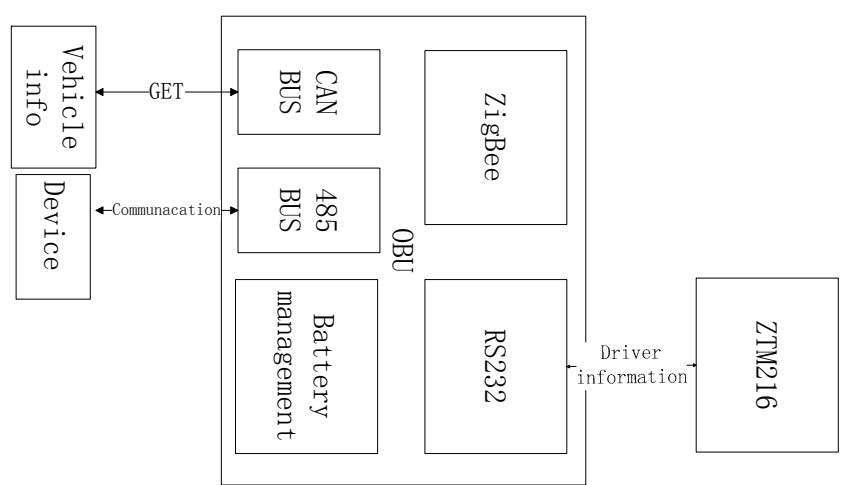

Fig.3 Design of OBU

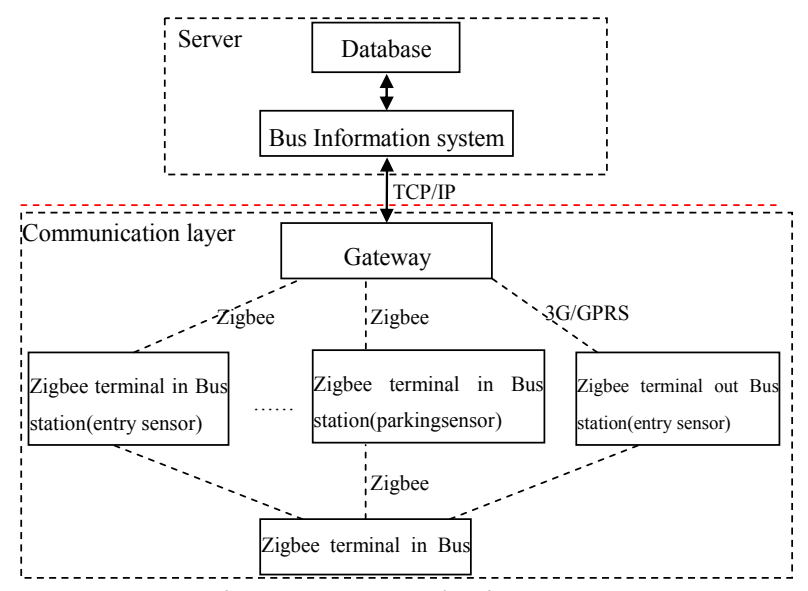

Fig.2 System design

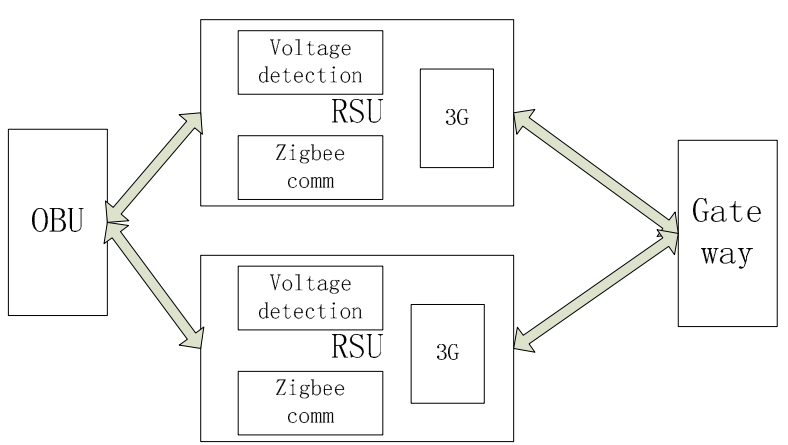

Fig.4 Design of RSU

Design of RSU.The RSU can be divided into three blocks, ZigBee security communication module, Voltage detection module, 3G module. ZigBee security communication module first receives data from the ZigBee network, and then through the serial transmission to the RSU control terminal. RSU control terminal and 3G modules are connected by a USB port, and finally the control terminal data obtained through the $3 \mathrm{G}$ module to upload to the Bus information system server.

\section{Application of Scene}

The application can be subdivided into four scenes:

1) Outer-station scene. RSU is installed in a few hundred meters distance from the station. When passenger vehicles reach the communication range of RSU, RSU and OBU begin to communication. According to the results, the server access vehicle identity information and comprehensive station crowded situation to determine whether to allow the car to enter the station and send information, passenger vehicle enter the nearby station information according to the information.

2) Entrance scene. RSU are installed in the station entrance, commutating with the OBU in the passenger vehicles and. One situation is the entrance has a control system, according to the decision results of the outer-station, control system decide whether to allow passenger vehicles entering the station by lifting the barrier; another situation is the entrance has not the entrance control system, vehicle information it is only to record into the system by the RSU.

3) Passenger station interior scenes, RSU is installed in the station yard, commutating with OBU. There are five functions. a) Congested situation monitoring of the get off area. b) The traffic safety area security monitoring. c) Abnormal situation monitoring of upper floors aisle, d) Monitoring of 
each floor entry vehicle. e) Parking location management, which is very important for the Start off district parking occupancy monitoring.

4) Station exit scene. RSU is installed at station exit. According to the result of communication decisions, the exit control system decides whether to allow passenger vehicles to exit by lifting the barrier.

\section{System deploy and Test}

The test system is installed in Guangzhou XiaTangXi Rd. Two RSUs and ten OBUs is the test object. Equipments for the test was list in Table 1. Fig.5 and Fig.6 show the photo of deployment of RSU and OBUs.

Table 1 Equipments under test list

\begin{tabular}{|c|c|c|l|}
\hline $\begin{array}{r}\text { Attrib } \\
\text { Type }\end{array}$ & Number & Power & \multicolumn{1}{c|}{ remark } \\
\hline RSU & 2 & $220 \mathrm{~V}$ & $\begin{array}{l}\text { RSU upload information, to the server by 3G server. } \\
\text { Get info by using TI Zigbee CC2530 chip and } \\
\text { CC2591 power amplifier. }\end{array}$ \\
\hline OBU & 10 & Battry & $\begin{array}{l}\text { Data source. Using the CC2530 chip and the security } \\
\text { chip Z32D1024 double MCU, with no amplifier }\end{array}$ \\
\hline Server & 1 & $220 \mathrm{~V}$ & $\begin{array}{l}\text { PC for receiving and displaying data . stored the } \\
\text { information into the database. }\end{array}$ \\
\hline
\end{tabular}

\section{Parameter configuration}

The networking mode: mesh network.

Transmit power: $21 \mathrm{dBm}$ (aggregation), $4.5 \mathrm{dBm}$ (vehicle, routing).

Roadside height: $2.5 \mathrm{~m}$.

Antenna Direction: vertical.

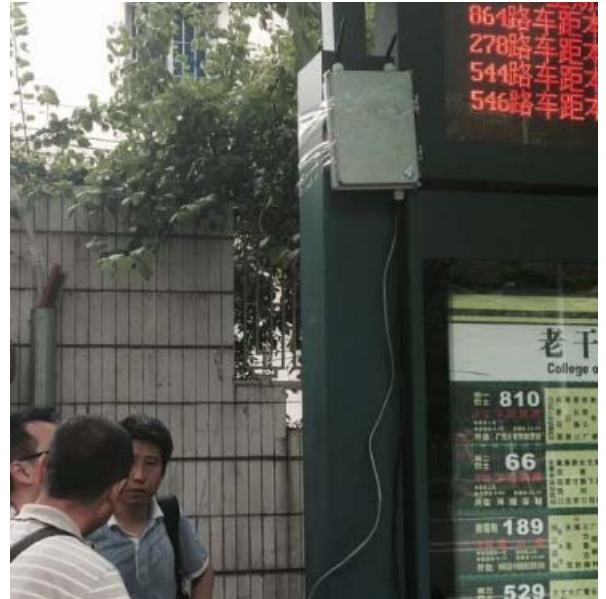

Fig.5 Deployment of RSU

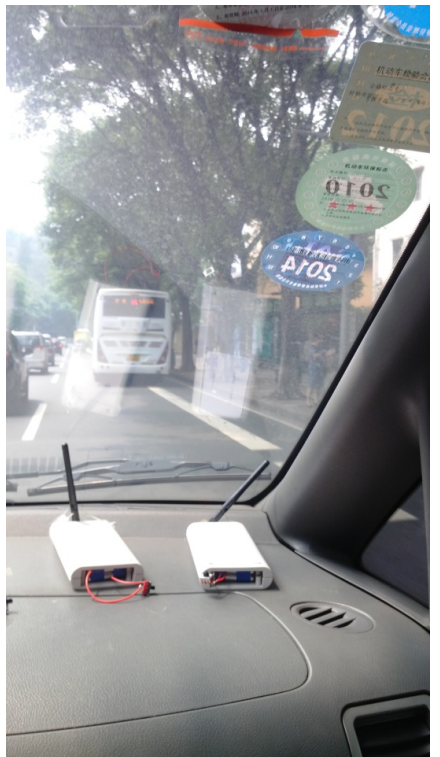

Fig.6 Deployment of OBU

\section{Parameter configuration}

There are four section of test.1) Communication link.Means to if the OBU can successfully upload information to the server. When the vehicle into the wireless sensor network range, ZigBee communication should begin. 2)Analysis of business data by the communaction protocol.3) the security of data encryption and decryption in Zigbee communacation.4)Concurrent communication.

Test Result. Through the statistics of test data, during a single vehicle mounted node test, OBU to RSU service data upload 14 pieces of business data (OBU + information transaction information, including 2 belonging to the retransmission) and successfully uploaded 12 pieces. Business data content re all right.Fig.7 shows that part of RSSI intensity value (dbm) is instability. 


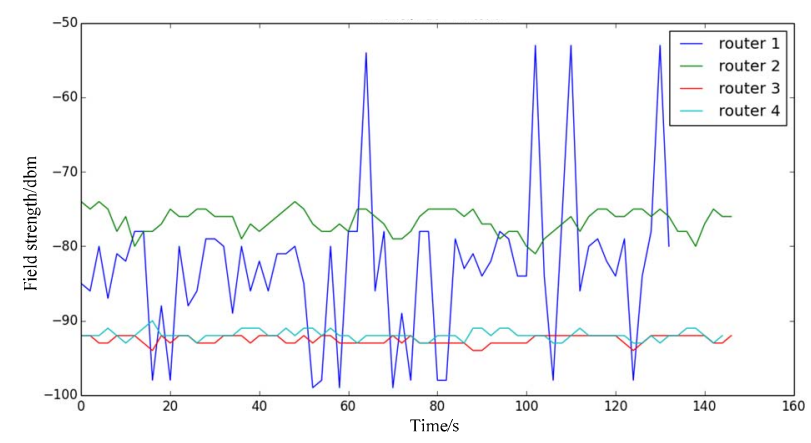

Fig.7 RSSI intensity value (dbm).

\section{Summary}

The test results show that the design and application of bus monitoring network is successful, to a certain extent to meet the needs of urban public traffic management.

\section{Acknowledgment}

These work is part of the project "Research of bus priority collaborative support system based on The Internet of Things"(2012-364-X18-107) which is promoted by Ministry of Transportation.

Specific thanks to the work of Cui Zongxing, Wu Dongxu, Zhang Zhe, Xiao Xiaoyang, Zhao Jiayu.

\section{References}

[1] Skyildiz I F Su W Sankarasubramaniam Y et al.Wireless sensor networks a survey[J].Computer Networks 2002384 393-422.

[2] ZigBee Alliance.ZigBee Specification1.0[OL].http://www.zigbee.org.

[3] Li Shan positions, Zhangke Wang. Principles and Applications of Wireless Sensor Networks [M]. Machine Press.2008.1.

[4] A. Bhatia and P. Kaushik, \&ldquo,A Cluster Based Minimum Battery Cost AODV Routing Using Multipath Route for ZigBee,\&rdquo, Proc. IEEE Int',1 Conf. Networks (ICON), Dec. 2008.

[5] R. Burda and C. Wietfeld, \&ldquo,A Distributed and Autonomous Beacon Scheduling Algorithm for IEEE 802.15.4/ZigBee Networks,\&rdquo, Proc. IEEE Int',1 Conf. Mobile Adhoc and Sensor Systems (MASS), Oct. 2007.

[6] F. Cuomo, S. Della Luna, U. Monaco and F. Melodia, \&ldquo,Routing in ZigBee: Benefits from Exploiting the IEEE 802.15.4 Association Tree,\&rdquo, Proc. IEEE Int',1 Conf. Comm. (ICC), June 2007.

[7] S. Gowrishankar, S.K. Sarkar and T.G. Basavaraju, \&ldquo,Performance Analysis of AODV, AODVUU, AOMDV and RAODV over IEEE 802.15.4 in Wireless Sensor Networks,\&rdquo, Proc. IEEE Int',l Conf. Computer Science and Information Technology (ICCSIT), Aug. 2009.

[8] S.A. Khan and F.A. Khan, \&ldquo,Performance Analysis of a ZigBee Beacon Enable Cluster Tree Network,\&rdquo, Proc. Int',1 Conf. Electrical Eng. (ICEE), Apr. 2009. 